Post-print de:

Carmen Bestué Salinas

"La traducción de términos jurídicos en el ámbito internacional " Babel, vol. 55, núm. 3 (2009), p. 244- 262, ISSN 0521-9744

DOI: 10.1075/babel.55.3.03bes 


\section{La traducción de términos jurídicos en el ámbito internacional}

Carmen Bestué

Autonomous University of Barcelona

\section{Introducción}

A primera vista podría parecer que el método comparatista, adoptado para la traducción de los términos de una determinada cultura jurídica, resultaría innecesario para la traducción de los términos propios del Derecho internacional. En efecto, puesto que el Derecho internacional es un ordenamiento supranacional y autónomo de los derechos internos o nacionales, sus términos deberían ser interpretados a la luz de su propio marco jurídico, sin necesidad de tomar en consideración los diversos contenidos nocionales que puedan tener atribuidos en las diferentes culturas jurídicas.

Sin embargo, del mismo modo que la doctrina utiliza el Derecho comparado para interpretar "los Principios Generales del Derecho reconocidos por las naciones civilizadas" - fuente primordial del Derecho internacional - también el traductor deberá utilizar el método comparativo para adoptar una u otra técnica de traducción. Puesto que el objetivo de los textos internacionales es obtener una aplicación uniforme de sus normas en cualquier jurisdicción, las diferentes versiones lingüísticas deben evitar los términos jurídicos propios de una cultura jurídica determinada - términos culturalmente marcados- ya que, al ser analizados y aplicados por los juristas de un país concreto, podrían producir desviaciones en su interpretación.

Muchas de las instituciones del Derecho internacional tienen su raíz en instituciones propias de una determinada cultura jurídica y, por lo tanto, su verdadero sentido únicamente puede aflorar a través del método comparativo:

the rule pacta sunt servanda, the idea behind the clausula rebus sic stantibus, and the theory of abus de droit in internacional law all have their roots in institutions of municipal private law, and it is only through comparative law that they can be made to yield their full potential (Zweigert 1998:8).

Los redactores de los tratados internacionales son plenamente conscientes de la influencia de las diferentes culturas jurídicas en la redacción de los textos inter-

Babel 55:3 (2009), 244-263. @ @ Fédération des Traducteurs (FIT) Revue Babel DOI 10.1075/babel.55.3.03bes ISSN 0521-9744 E-ISSN 1569-9668 nacionales y del papel fundamental que desempeña la lengua de trabajo como elemento transmisor de posibles transplantes legales. Sin embargo, los autores que más claramente han alertado sobre estos riesgos son los juristas franceses. Estos autores, sensibilizados por la pérdida de hegemonía de su cultura jurídica que, entre otros factores, supuso el abandono del francés como lengua de la diplomacia, son los que más claramente se han posicionado para evitar que la lengua de trabajo, el inglés mayoritariamente, conlleve la implantación de instituciones anglosajonas cuando ello no sea estrictamente necesario. Puesto que la lengua como vehículo de comunicación tiene gran importancia sobre el contenido que se transmite, y que los textos internacionales son redactados - en régimen de corredacción - o traducidos a diferentes idiomas, los juristas del ámbito internacional prestan mucha atención a las diferentes versiones lingüísticas y ponen especial esmero en crear barreras o cortafuegos lingüísticos para evitar una completa hegemonía de los conceptos jurídicos propios de una única cultura jurídica.

En el presente artículo veremos algunos ejemplos de traducciones de los Principios de Derecho Europeo de las Contratos y las compararemos con otras soluciones extraídas de textos internacionales que regulan diferentes aspectos de la contratación internacional. En primer lugar, presentaremos el ámbito jurídico en el que se circunscriben los textos examinados para, en segundo lugar, analizar las diferentes traducciones. Por último, concentraremos nuestra atención en las traducciones al español de los Principios de Derecho Europeo de los contratos para examinar las equivalencias adoptadas por sus autores.

\section{Los textos del ámbito internacional en materia de Derecho contractual}

Basta una simple ojeada al número de páginas que contiene un contrato tipo en inglés y otro redactado originalmente en español para ver cómo las diferencias de fondo existentes en esta materia se ven reflejadas en su tratamiento textual, tanto en el plano formal como en el terminológico. Sin embargo, el tratadista internacional y los diferentes grupos privados de académicos concentran sus esfuerzos en destacar los puntos en común que reúnen los diferentes ordenamientos jurídicos con el objeto de extraer unos principios generales que sean reconocibles para la mayoría de los países.

1. Además de los instrumentos que analizamos en el presente trabajo podemos citar las propuesas realizadas por Study Group on a European Civil Code y The Pavia Group on an European Contract Code. En puridad estos textos por su naturaleza no imperativa no serían considerados como Derecho y mucho menos adscritos a la categoría del Derecho internacional "strictu sensu", a este respecto véase Díez Picazo et al. (2002:141-4).Sin embargo, otros autores defienden su inclusión en el Derecho internacional en su calidad de instrumentos inspiradores y uniformizadotes que constituyen normas internacionales de Derecho uniforme, véase Forner et al. (2006:26) 
Este núcleo de principios comunes se vio reflejado en los Principios elaborados por Unidroit ${ }^{2}$ (1994) para regular los Contratos Comerciales Internacionales. El objetivo de los redactores de este texto era fijar unas reglas generales para el tráfico mercantil internacional en el marco de un proceso de unificación jurídica, no legislativa, mediante la recopilación y ordenación del Derecho contractual internacional. ${ }^{3}$ De igual modo, la llamada Comisión Lando ${ }^{4}$ sobre el Derecho contractual europeo elaboró en 1994 los Principios de Derecho Europeo de Contratos ${ }^{5}$ (en adelante mencionados por sus siglas en inglés PECL).

El antecedente de dichos instrumentos internacionales fue la Convención de las Naciones Unidas sobre los contratos de compraventa internacional de mercaderías de 11 de abril de 1980, conocida como Convención de Viena que en adelante citaremos por sus siglas en español CCIM. ${ }^{6}$

Los textos citados - sin incluir aquí el CCIM que sí es un Tratado internacional y por lo tanto imperativo en aquellos países que lo hayan ratificado - tienen una clara voluntad de ser aceptados por el mayor número de países ya que, al carecer de fuerza vinculante, su aplicación depende de que las partes los incorporen a su contrato o lo sometan a los mismos. ${ }^{7}$ Sus redactores se propusieron lograr la mayor neutralidad posible entre los diferentes sistemas de Derecho y, por lo tanto,

2. Unidroit es el Instituto Internacional para la Unificación del Derecho Privado, conocido también como Instituto de Roma.

3. Los supuestos de incumplimiento contractual están recogidos en el capítulo 7. Estos principios no ven restringido su ambito de aplicación al concepte mercantil tal como se entiende e España (por contraposición con los contratos civiles) sino que tienen vocación de ser aplicados a todos los contratos que no se celebren con consumidores.

4. En el origen de estos Principios, al igual que en los de Unidroit, estuvo el profesor Ole Lando quien fue su fundador y primer Presidente de la Comisión de Derecho Europeo de los contratos creada con la finciacion y el apoyo de la Comision de la entonces Comunidad Europea Los Principios han sido elaborados en tres partes y en el presente artículo nos limitaremos a analizar las Partes I y II que han sido revisadas. Hasta la fecha han sido representantes españoles ante la Comisión los profesores Alberto Berchovitz, Pablo Salvador Coderch y Fernando Martínez Sanz 5. El texto fue redactado originalmente en inglés, y ésta es la versión oficial. No se produjo ninguna traducción oficial de los mismos. En la página web figura la traducción de Pilar Barres, J.M. Embid y Fernando Martínez Sanz (http://frontpage.cbs.dk/law/commission_on_european_contract_law/Skabelon/pecl_spansk.htmlink) pero en ningún momento aparece como la única autorizada.

6. En la actualidad, más de cincuenta países forman parte de la Convención de Viena, Convention on International Sales of Goods, conocida por su acrónimo en inglés CISG y también citada por su acrónimo en español CNUCCIM o la versión abreviada que aquí utilizamos CCIM). Para más información sobre esta materia véase Perales (2001).

7. El artículo 1:101 PECL prevé otros supuestos de aplicación de los principios, entre otros la mención a los "principios generales del derecho" o la lex mercatoria evitar los términos jurídicos demasiado marcados por una cultura jurídica determinada. Sin embargo, en ocasiones, se mantiene el uso de una terminología tradicional de un sistema jurídico pero se busca compensarla con otra institución perteneciente a otro sistema jurídico. En la CCIM, por ejemplo, encontramos términos típicamente romanistas a los que se les añade alguna institución anglosajona con objeto de completar y enriquecer el texto legal. Así, la indemnización de daños y perjuicios se encuentra regulada en el artículo 74 de la Convención y refleja los conceptos romanistas del "daño emergente" y "el lucro cesante", pero se añade la obligación de mitigar los daños regulada por el Common law.

En cambio, los textos internacionales ${ }^{9}$ posteriores, en concreto, los principios de Unidroit y los PECL, intentan evitar el uso de términos propios de una determinada cultura jurídica y en su redacción original, en lengua inglesa, prefieren acepciones más genéricas tales como: "non-performance" en lugar de "breach of contract", o "reasonable loss" en lugar de enumeraciones del tipo "indirect, consequential, special damages..."

A continuación, en el ejemplo (1) recogemos unos preceptos de la Convención de Viena y los PECL donde se ve una variación terminológica neutralizadora en el caso de este último texto.

Aún así, el marco general de los PECL refleja un gran influjo de la visión anglosajona de los contratos en la cual prima la función económica del contrato, ya que como su propio redactor, el profesor Lando, reconoce en la página web "the Commission has tried to establish principles which it believed had regard to the economic and social conditions in Europe".

Estos textos son fruto del consenso de los juristas participantes quienes representan a sus diferentes culturas jurídicas. En el caso de los PECL todos los países que pertenecían a la entonces Comunidad Europea estaban allí representados. Ahora bien, para cada capítulo se seleccionaba un redactor que se intentaba perteneciera a un ordenamiento jurídico cuyas aportaciones en esa materia fue-

8. Si bien la redacción de la Convención de Viena parece muy similar a la que se encuentra en los textos del UCC y el Restatement second on contracts, se basa en términos de contenido tan variable "had reason to know", "foreseeable probable damages", "foresaw or ought to have foreseen" que finalmente los tribunales nacionales que tienen que aplicar los textos internacionales pueden caer en la tentación de interpretarlos de la forma que más se aproxime a su propio derecho. Esto es lo que sucedió en el asunto Delchi Carrier SPA v Rotorex Corp. Para más información sobre las diferentes interpretaciones de la limitación de la previsibilidad en Derecho de daños, véase Schneider (1995)

9. En puridad no se trataría de textos internacionales ya que son el fruto del trabajo de agrupaciones privadas de iusprivatistas sin embargo por su ámbito de aplicación, el internacional para los principios de Unidroit, y el de los países de la Unión europea (tanto en su ámbito nacional como intracomunitario) se suelen considerar en esta categoría. Díez Picazo et al. (2002:142) son categóricos al afirmar que no son textos del Derecho internacional.

\section{2nd proofs}


Ejemplo 1

\begin{tabular}{|l|l|}
\hline CCIM & PECL \\
\hline $\begin{array}{l}\text { Art. 25 Breach of contract se refiere al } \\
\text { incumplimiento esencial de las condiciones } \\
\text { del contrato }\end{array}$ & $\begin{array}{l}\text { Art. 1:301: Non performance (inejecución } \\
\text { o no cumplimiento) que abarca tanto } \\
\text { el cumplimiento defectuoso, como } \\
\text { el incumplimiento definitivo de una } \\
\text { obligación, el incumplimiento de una } \\
\text { obligación accesoria y el incumplimiento } \\
\text { retrasado. }{ }^{b}\end{array}$ \\
\hline
\end{tabular}

En este caso se utiliza la terminología anglosajona breach of contract pero descontextualizada de su cultura jurídica por lo que si bien en el Derecho anglosajón el remedio automático del breach of contract es la indemnización de daños y perjuicios, en el contexto de la CIGS esta solución no será adoptada de forma sistemática, (véase Alpa 1996: 680, citado en Onufrio 2004:9).

Para un analisis mas detallado de los supuestos que incluye el incumplimiento contractual regulado en los PECL y la diferencia con el Derecho español véase Diez Picazo et al. (2002:322). Y para un análisis comparado entre los efectos del incumplimiento contractual en la CCIM y los PECL, véase (Navas

ran destacables. De este modo, para la redacción del capítulo sobre los damages se seleccionó a un ponente inglés, para el capítulo sobre Authority of the Agent se seleccionó a un alemán y para las normas sobre force majeure y hardship fue un francés el escogido. Con posterioridad los ponentes se reunían con un grupo en el que figuraban juristas que representaban a todas las familias del Derecho europeo y, una vez que llegaban a un acuerdo sobre el contenido, se proponía a un Grupo encargado de la redacción en inglés. Las traducciones se realizaron a posteriori y aunque una figura en la página web ${ }^{10}$ de la Comisión ninguna traducción ha sido expresamente declarada como oficial.

La consecuencia más destacada de la falta de traducción oficial se ve materializada en las diferentes acepciones que reciben dichos principios en su denominación: "Principios Del Derecho Europeo De Contratos" (Díez Picazo et al. 2002), "Principios Europeos de Derecho de los Contratos" (Navas 2000), "Principios de derecho europeo de los contratos" (Martínez et al. 2003), "Principios de Derecho contractual europeo" (Martín 2002 y Forner 2006).

Por lo que respecta a los aspectos formales de la estructura de los referidos documentos podemos destacar que la división de los principios, tanto de Unidroit como de los europeos, se articula en una forma coincidente con el ámbito internacional y las codificaciones tradicionales europeas, es decir que el artículo - al contrario del Derecho anglosajón donde esta parte se denomina section - es la división elemental donde se recoge la norma. Sin embargo, la numeración adopta el formato anglosajón (1:101,1:102 ..), a priori más complicado para su citación pero que,

10. En la página web de la comisión de Derecho europeo de los contratos figura la traducción realizada por Pilar Barnes, y J.M. Embid , que cuenta con la revisión del Profesor Fernando Martínez Sanz quien es el actual representante español en la Comisión.

Ejemplo 2
\begin{tabular}{|l|l|}
\hline PECL & UNIDROIT \\
\hline Parte & Preámbulo \\
Capítulo & Capítulo \\
Sección & Sección \\
Artículo & Artículo \\
Título del artículo & Título del artículo \\
Número complejo. Ej. & Número complejo. Ej. \\
2:209 Conflicting General Conditions & 2.1 .22 Battle of forms \\
\hline
\end{tabular}

en cambio, facilita su localización en el texto por lo que resulta más sistemático. ${ }^{11}$

En el anterior ejemplo (2) recogemos la estructura comparada de los apartados de los PECL y los principios de Unidroit.

\section{La traducción de los textos internacionales sobre los contratos}

En el Derecho internacional, los juristas se muestran siempre alerta ante el fenómeno de la traducción, que se percibe como algo peligroso. Así, los juristas al frente de la Comisión Lando para la elaboración de los Principios del Derecho Europeo de Contratos, estaban muy preocupados por el peligro que suponía el hecho de que la lengua de trabajo fuera el inglés y querían evitar a toda costa que la primacía de la lengua conllevara la primacía del ordenamiento jurídico anglosajón, porque, como Tallon (1999:32) reconoce: "le mot anglais appelle le concept anglais. C'est à l'autre langue de s'aligner." ${ }^{12}$ Por esta razón los juristas intentaron conseguir una neutralidad total entre los sistemas romanistas y de la Common law y para ello se sirvieron del lenguaje, creando una terminología jurídica que no pudiera ser atribuible a un Derecho nacional concreto. Como el objetivo era conseguir que las diferentes versiones del texto expresaran lo mismo, los redactores pusieron un énfasis especial en evitar los términos "trop marqués par une culture juridique"13 Chatillon (2002:691) y primaron, por tanto, la utilización de términos neutros. Nos encontramos con un texto que trata de evitar por todos los medios las palabras demasiado técnicas, con un abuso de las perífrasis explicativas que puede crear un idioma demasiado farragoso pero con un fin muy claro: evitar el error.

1. Así por ejemplo, el artículo 1:101 pertenece al capítulo 1 , sección 1 y es el artículo 1; el artículo 2:301 pertenece al capítulo 2 (formation), sección 3 (liability for negotiations) y es el artículo 1 que lleva por título Negotiations Contrary to Good Faith.

12. "La palabra en inglés refleja el concepto inglés y es la otra lengua la que tiene que alinearse" (esta traducción y las demás donde no se indique lo contrario son de la autora).

13. "Demasiado marcados por una cultura jurídica".

\section{2nd proofs}


Este objetivo, el de evitar el error, debe primar asimismo cuando se trata de la traducción de textos que no pertenecen al ámbito internacional. Sin embargo, tal como indica Tallon, ello no debe justificar caer en la traducción literal cuando ésta no es necesaria, ni dejarse llevar por la apariencia de las palabras para reproducirlas sin tener en cuenta su contenido. Así, por ejemplo, el concepto inglés de good faith no tiene el mismo alcance que los términos etimológicamente idénticos utilizados en los países de tradición romano-germánica como sería la expresión en español "buena fe". ${ }^{14}$ Por ello, en la versión en inglés del artículo 1.7 de los Principios de Unidroit, se decidió recoger la expresión good faith and fair dealing. La versión en francés tradujo la expresión inglesa por bonne foi, y lo mismo hicieron las versiones italianas y alemanas, sin embargo la versión española se limitó a calcar la frase inglesa y se puede leer "buena fe y lealtad negocial". En su exceso de celo por la traducción literal, el traductor español prefirió "sacrificar" la institución tan propia del Derecho nacional y adoptar tal cual los términos de la lengua de partida. ${ }^{15}$

La redacción de los Principios de Unidroit y los PECL refleja una clara intención de neutralización del lenguaje jurídico por lo que abundan las perífrasis y el empleo de términos del lenguaje común que no tienen una connotación jurídica marcada en las respectivas culturas jurídicas ya que el objetivo es, en este contexto, lograr que los jueces que deban aplicar dichos principios no se dejen llevar por su propio Derecho nacional. A título de ejemplo podemos citar la utilización de la expresión "cumplimiento específico"16 para expresar lo que en Derecho español se conoce tradicionalmente como "ejecución o cumplimiento in natura", de "terminación" del contrato en lugar de "resolución" o, también, "exoneración debida a un impedimento" en lugar de "fuerza mayor".

Por otro lado, la particular situación comunicativa, que justifica las técnicas de traducción utilizadas en los textos internacionales, no se reproduce cuando un traductor recibe el encargo de traducir un contrato redactado en inglés pero al que le será aplicable un Derecho nacional, sea éste el inglés, el estadounidense o el español. En efecto, el propio Tallon considera que el término inglés reliance no es propio del Derecho francés y, por lo tanto, no se puede transplantar tal cual. Sin embargo, cuando traducimos fuera del ámbito del Derecho internacional, no

14. La buena fe en español abarca tanto el sentido objetivo del término, la lealtad, como el sen tido subjetivo.

15. Esta expresión es el equivalente literal del inglés "specific performance", sin embargo hoy en día su uso ya está tan extendido en la doctrina que podría ser considerado una suerte de neologismo jurídico. Lo mismo sucede con la traducción del concepto anglosajón damages (indemnización de daños y perjuicios) por daños, hoy en día incluso en las Facultades de Derecho los especialistas de la responsabilidad extracontractual se denominan especialistas del Derecho de daños, creando confusión e interferencias con la figura de los torts anglosajones.

16. Véase, por ejemplo, Clemente (1998:587) podemos olvidar un factor muy importante y es que el traductor es el mediador en un proceso de comunicación en el que probablemente su receptor es un jurista que conoce la doctrina jurídica de su país donde ya se han producido numerosos transplantes aunque muchos de ellos no hayan fructificado, es decir, no se hayan incorporado propiamente hablando al Derecho nacional. Así, lo que el traductor debe comprobar es cómo ha realizado la transposición lingüística la doctrina y, en el caso del término reliance, podemos constatar cómo los autores españoles utilizan este concepto y lo denominan "interés de confianza". ${ }^{17}$ En un contexto de traducción referencial, por lo tanto, "interés de confianza" será un equivalente funcional de reliance a pesar de que el Derecho positivo no lo contemple. Lo mismo sucede con términos propios de otras culturas jurídicas como serían los conceptos franceses de obligation de moyens et obligation de résultat; se trata de conceptos desarrollados por la doctrina y la jurisprudencia francesas a partir del artículo 1147 del Código civil francés y prácticamente todos los contratos de prestación de servicios redactados en francés contienen dichos términos. En español no se suelen incluir en los contratos redactados conforme al Derecho nacional, sin embargo la doctrina los utiliza normalmente y se refiere a ellos como "obligación de medios" (o de actividad) y "obligación de resultado". ${ }^{18}$ Los principios de Unidroit, en cambio, han preferido realizar una perífrasis que muestra la influencia del idioma de trabajo, el inglés, ya que dichas expresiones se traducen en español por "obligación de resultado y obligación de emplear los mejores esfuerzos" (best efforts). ${ }^{19}$

De lo dicho hasta ahora se deduce que la labor de documentación del traductor de textos jurídicos no debe limitarse a investigar en las fuentes lexicográficas y del Derecho positivo español sino que debe abarcar también las obras de la doctrina, ya que se trata de las fuentes donde mejor podrá contrastar si algunas instituciones jurídicas foráneas se encuentran lingüísticamente transplantadas al español. El concepto de equivalente funcional debe por tanto modularse según la función o método general de la traducción y puede ser más amplio cuando el Derecho aplicable no es el español.

En otros contextos, la labor de documentación del traductor se simplifica ya que basta con acudir a las fuentes originales, los códigos, para encontrar los

17. Véase, por ejemplo, Díez Picazo, (1999:249) o Trigo (1999:241)

18. Los principios de Unidroit son un ejemplo de lenguaje poco natural y a veces forzado, que deja transparentar el término en inglés. Así, por ejemplo, se utilizan expresiones como: cumplimiento en un solo momento o en etapas (art. 6.1.2), cambio de remedio (art. 7.2.5), daño no pecuniario (art. 7.4.2-2), suma global (7.4.11), etc. Se habla de una preferencia por los términos neutros cuando en realidad se ve una influencia clara no sólo del idioma inglés sino del sistema jurídico anglosajón.

19. En estos casos el equivalente utilizado es contextual ya que en las obras lexicográficas encontramos diferentes equivalencias pero no podremos seleccionar una u otra sin acudir al contexto.

\section{2nd proofs}


equivalentes funcionales dentro de su contexto. Así, sucede con términos del francés como faute que corresponde al término español "culpa" y no a "falta" (artículo 1902 Código civil y 1383 Código civil francés) o también la responsabilité délictuelle que corresponde al término en español "responsabilidad extracontractual" y no a la responsabilidad derivada de delito o responsabilidad criminal como etimológicamente podría parecer. ${ }^{20}$

\section{Las traducciones españolas de los PECL}

Tal como hemos indicado, la Comisión de Derecho europeo de los contratos, presidida por el Profesor Ole Lando, conocida por ello como la Comisión Lando, preparó los PECL en inglés. Las versiones lingüísticas que aparecen en la página web de la Comisión no tienen la consideración de oficiales. En nuestro artículo trabajaremos con dos traducciones al español, la primera (A) es la que aparece en la página web, que ha sido realizada por Pilar Barnes y J.M. Embid y que ha contado con la revisión del actual representante español en la Comisión, el profesor Fernando Martínez Sanz. Se trata de una traducción no encubierta en la que los traductores comparten con los lectores sus decisiones de traducción a través de las numerosas notas a pie de página. En cuanto a las decisiones estilísticas, se mantiene la función referencial del articulado y se respeta su formato, de este modo tanto el lector español como el inglés podrán citar los artículos del mismo modo.

La segunda traducción analizada (B) es la que aparece en la obra de Díez Picazo, Roca Trías y A.M. Morales "Los principios del Derecho europeo de contratos". Estos autores no explican sus decisiones de traducción, ni siquiera el grado de participación de cada uno de ellos en la traducción, pero sin embargo reconocen en su proemio:

Hemos incorporado a este libro una traducción castellana de los Principios de nuestra propia cosecha, pues, aunque es operación siempre arriesgada, el trabajo de divulgación que pretendemos quedaría sin ella falto de un instrumento muy importante (Díez Picazo et al. 2002: 18).

Se trata de una traducción encubierta que tiene por objeto divulgar el texto entre los lectores de castellano. En ningún momento, ni en el texto de la traducción ni en resto de la obra que analiza los Principios, se comentan las decisiones de traducción; sin embargo, creemos que los autores se han marcado un objetivo de traducción orientada a la cultura meta, ya que al explicar la técnica utilizada por los redactores de los Principios explican que "han utilizado una aproximación fun-

20. http://frontpage.cbs.dk/law/commission_on_european_contract_law/Skabelon/pecl_ spansk.htmlink) cional", se concentran más en "las soluciones que en cada uno de los sistemas se dan específicamente a cada uno de los problemas" y ello comporta dejar de lado las diferentes terminologías. Desde un punto de vista estilístico, por ejemplo, esta traducción numera los artículos de forma seguida, como si los artículos comenzaran en el 1.101, suprimen por tanto los “:” que se utilizan en la versión en inglés.

Ejemplo 1 de traducción

\begin{tabular}{|l|l|}
\hline Artículo & Versión en inglés \\
\hline Article 1:201: & $\begin{array}{l}\text { Good Faith and Fair Dealing } \\
\text { (1) Each party must act in accordance with } \\
\text { good faith and fair dealing }\end{array}$ \\
\hline Artículo & Versión en español (A) \\
\hline Artículo 1:201: & $\begin{array}{l}\text { Cada parte tiene la obligación de actuar } \\
\text { conforme a las exigencias de la buena fe. }\end{array}$ \\
\hline Artículo 1.201. & Versión en español (B) \\
\hline & $\begin{array}{l}\text { Cada parte debe actuar de acuerdo con la } \\
\text { buena fe y la lealtad }\end{array}$ \\
\hline
\end{tabular}

En este caso el traductor (A) justifica, mediante una nota a pie de página, que el contenido nocional de la expresión en inglés "good faith and fair dealing" está perfectamente recogido dentro del equivalente funcional en español "buena fe" $\mathrm{y}$ por lo tanto evita el calco del inglés que, desde un punto de vista conceptual, no aporta mayor claridad. En cuanto a la sintaxis, se aleja de la del texto original y utiliza la fraseología acuñada en español y por lo tanto natural en este idioma como es la recogida en el artículo 7 del Código civil "conforme a las exigencias de la buena fe".

La traducción (B) reproduce completamente la sintaxis del inglés y traduce el sintagma verbal de obligación must act de forma literal sin adaptarlo a formas más naturales en español, como sería el verbo en su tiempo futuro, y además traduce la expresión en inglés good faith and fair dealing por "buena fe y lealtad" aunque reconoce que el concepto español de "buena fe" ya incluye la "lealtad". Los autores proclaman que la mayoría de las diferencias entre los diferentes ordenamientos jurídicos son "más lingüísticas que otra cosa" (Díez Picazo et al. 2002: 78). Así mismo, en su análisis reconocen que "la buena fe es un concepto extraño en el Common Law." (Díez Picazo et al. 2002:99) mientras que más adelante afirman "la buena fe y la lealtad (...) de acuerdo con la tradición que nosotros profesamos, ambas ideas se funden en un mismo concepto "(Díez Picazo et al. 2002:157). 
Ejemplo 2 de traducción

\begin{tabular}{|l|l|}
\hline Artículo & Versión en inglés \\
\hline Article 1:301: (3) & $\begin{array}{l}\text { An 'intentional' act includes an act done } \\
\text { recklessly. }\end{array}$ \\
\hline Artículo & Versión en español (A) \\
\hline Artículo 1:301: (3) & $\begin{array}{l}\text { El concepto de una acción 'intencional' } \\
\text { incluye también un acto gravemente } \\
\text { negligente }\end{array}$ \\
\hline Artículo 1.301. (3) & Versión en español (B) \\
\hline & $\begin{array}{l}\text { Acción "intencional" incluye los actos } \\
\text { realizados imprudentemente. }\end{array}$ \\
\hline
\end{tabular}

En este caso el traductor (A) reconoce, con una nota a pie de página, la dificultad a la hora de traducir el término recklessly que básicamente se ha utilizado en el texto para excluir las conductas meramente negligentes equiparables al dolo even tual, pero como este concepto es más propio del Derecho penal, prefieren utilizar una traducción explicativa o perifrástica como "gravemente negligente". Los autores de la traducción (B) continúan con una traducción literal en la que, sin embargo, se permiten utilizar un equivalente que pertenece al Derecho penal, solución que no siempre es la más recomendable ya que puede complicar la interpretación de su contenido nocional estricto. ${ }^{21}$

Ejemplo 3 de traducción

\begin{tabular}{|l|l|}
\hline Artículo & Versión en inglés \\
\hline Article 2: 101: & Conditions for the Conclusion of a contract \\
\hline Artículo & Versiones en español \\
\hline Artículo 2:101: & $\begin{array}{l}\text { (A) Condiciones para la conclusión de un } \\
\text { contrato }\end{array}$ \\
\hline Artículo 2.101. & $\begin{array}{l}\text { (B) Condiciones para la conclusión del } \\
\text { contrato }\end{array}$ \\
\hline
\end{tabular}

En este caso la ligera variación que produce el uso del artículo determinado o indeterminado no creemos que merezca mayor comentario. Sin embargo sí queremos detenernos en el hecho de que se traduzca el verbo inglés conclusion por "conclusión del contrato" cuando en la práctica esta expresión no se suele utilizar y resulta más natural una formulación más común como sería "celebración". El término "conclusión" en la lengua general sólo tiene la acepción de "terminación o

21. De hecho Terral (2002:42) recomienda no utilizar el equivalente funcional con los término que pertenecen a otros ámbitos del Derecho. finalización". Además es con este sentido que el Código civil lo utiliza en sus artículos 1392 a 1410 cuando habla de la "conclusión de la sociedad de gananciales". Si bien es cierto que el término "conclusión del contrato" se viene utilizando en los contratos de seguros y que la propia Ley sobre los contratos de seguros así lo recoge en su artículo 4, creemos que su uso todavía no se ha extendido a otro tipo de contratos y, por ello, otra fórmula hubiera sido más acertada. De hecho, los autores cuando analizan esta cláusula prefieren utilizar "la celebración del contrato" y en ningún momento, aparte de la traducción, retoman la expresión "conclusión del contrato". 22

Ejemplo 4 de traducción

\begin{tabular}{|l|l|}
\hline Artículo & Versión en inglés \\
\hline Article 4:107: & $\begin{array}{l}\text { Fraud } \\
\text { 2) A party's representation or non-disclosure } \\
\text { is fraudulent if it was intended to deceive. }\end{array}$ \\
\hline Artículo & Versión en español (A) \\
\hline Artículo 4:107: & $\begin{array}{l}\text { Dolo } \\
\text { 2) La actuación de la parte o su silencio son } \\
\text { dolosos si su objeto era engañar. }\end{array}$ \\
\hline Artículo 4.107. & Versión en español (B) \\
\hline & $\begin{array}{l}\text { Dolo } \\
\text { 2) La representación de la parte o la no } \\
\text { revelación de información son fraudulentas } \\
\text { si se realiza con el intento de engañar. }\end{array}$ \\
\hline
\end{tabular}

En este ejemplo hemos de destacar que la traducción (B) incurre en un problema de incoherencia terminológica y además realiza un calco que puede inducir a oscurecer el precepto. En efecto, en el título los traductores deciden que en este contexto el sentido de fraud corresponde al concepto civil del "dolo", es decir la voluntad maliciosa de engañar a otro, y no al penal de "fraude". Sin embargo, en la formulación del artículo se pega al original y prefiere el equivalente literal "fraudulentas". Esta técnica de optar dentro de un mismo articulo y para un mismo término, en una ocasión, por un equivalente literal y, en otra, por el equivalente funcional, genera incoherencia y confusión en el lector. Por nuestra parte, para la traducción de fraudulent representation hubiéramos seleccionado la terminología más próxima a utilizada en el artículo 1269 del Código civil español

22. La traducción al francés también refleja el término "conclusion $d u$ contrat" pero en este caso está justificado ya que el diccionario jurídico de Cornu recoge expresamente esta acepción "Opération par laquelle les parties contractantes s'engagent et qui donne naissance à leur accord (qu'il s'agisse de personnes privés ou de sujets de Droit international)". Los diccionarios jurídicos españoles que hemos consultado no recogen esta acepción.

\section{2nd proofs}


"maquinaciones dolosas". En cuanto a la traducción literal del término inglés representation por "representación" creemos que es un calco a evitar, el Código civil no lo utiliza en el sentido de "manifestación, actuación, declaración" y a pesar de que ya lo vamos encontrando en muchos textos especializados, no creemos que aporte nada a la buena comprensión del texto.

En la traducción (B) vemos como nuevamente en el título los traductores optan por el calco o traducción literal cuando en realidad están cometiendo un falso sentido, ya que en este caso "damages" no es el plural de "damage", es decir, "daño" sino el concepto jurídico desarrollado por el Common Law como derecho adjetivo para los supuestos tanto de responsabilidad contractual como extracontractual y que consiste siempre en la indemnización económica, ${ }^{23}$ es decir lo que en español expresamos en terminología tradicional como "indemnización de daños y perjuicios". De hecho el Derecho anglosajón conoce incluso la indemnización para el supuesto de que no se haya producido un daño (damage). Tal como hemos adelantado, el concepto del Derecho de daños está ya tan implantado en la terminología jurídica española que no merece seguir profundizando en el tema; sin embargo, creemos que lo correcto sería delimitar su ámbito de aplicación, como así proponemos:

- Torts: Derecho de daños

- Damages: Indemnización de daños y perjuicios

Desde un punto de vista terminológico, la traducción (B) prefiere utilizar los términos jurídicos literales ("remedio" por "remedy"). Sin embargo, en cuanto a la construcción sintáctica, se permite alejarse del original y para nosotros resulta mucho más clara que la redacción en inglés y también que la versión (A). La traducción (A) opta por no repetir el término "acciones" y sustituirlo por "medios" al final y creemos que ello oscurece la interpretación de este precepto que de por sí resulta confuso en su redacción original. En este ejemplo los juristas que han traducido la versión (B) se han visto confrontados a uno de los mayores quebraderos de cabeza que tiene el traductor, a nuestro entender el mayor, adaptar las estruc turas sintácticas del inglés a la retórica más perifrástica del español, por ello han optado por una traducción menos literal que sí transmita el sentido. En este caso la versión francesa de los principios es la que nos parece más clara ya que esta len gua cuenta con el conector "qui" que permite construir la frase y limitar su inter-

23. Según la definición de Mcgregor (2003) el término damages corresponde a: the pecuniary compensation, obtainable by success in an action, for a wrong which is either a tort or a breach of contract, the compesation being in the form of a lump sum awarded at one time, unconditionally and in sterling. (la compensación económica que puede ser obtenida previa reclamación, por responsabilidad contractual o extracontractual, y que consiste en un único pago a tanto alzado, incondicional y en libras esterlinas)

\begin{tabular}{l} 
Ejemplo 5 de traducción \\
\begin{tabular}{|l|l|}
\hline Artículo & Versión en inglés \\
\hline Article 4:117: & $\begin{array}{l}\text { Damages } \\
\text { 1) A party who avoids a contract under this } \\
\text { Chapter may recover from the other party } \\
\text { damages so as to put the avoiding party as } \\
\text { nearly as posible into the same position as if } \\
\text { it had not concluded the contract, provided } \\
\text { that the other party knew or ought to have } \\
\text { known of the mistake, fraud, threat or taking } \\
\text { of excessive benefit or unfair advantage. }\end{array}$ \\
\hline Artículo & Versión en español (A) \\
\hline Artículo 4:117: & $\begin{array}{l}\text { Daños y perjuicios } \\
\text { 1) La parte que denuncie un contrato en } \\
\text { virtud del presente capítulo podrá solicitar } \\
\text { de su contraparte una indemnización por } \\
\text { daños y perjuicios que le permita volver a } \\
\text { una situación lo más parecida posible a la } \\
\text { que obtendría de no haberse celebrado el } \\
\text { contrato, siempre que la otra parte hubiera } \\
\text { sabido o hubiera debido saber que existía } \\
\text { error, dolo, intimidación, un beneficio } \\
\text { excesivo o una ventaja injusta. (negrita } \\
\text { añadida) }\end{array}$ \\
\hline Artículo 4.117. & Versión en español (B) \\
\hline & $\begin{array}{l}\text { Daños } \\
\text { 1) La parte que anule el contrato de } \\
\text { acuerdo con este capítulo, puede reclamar } \\
\text { de la otra una indemnización de daños } \\
\text { que la coloquen en una situación lo más } \\
\text { parecida posible a aquello en que se hubiera } \\
\text { encontrado si no hubiera celebrado el } \\
\text { contrato, siempre que la otra parte conociera } \\
\text { o debiera haber conocido el error, el fraude, } \\
\text { la amenaza o la obtención de beneficios } \\
\text { excesivos o la ventaja indebida. (negrita } \\
\text { añadida) }\end{array}$ \\
\hline
\end{tabular} \\
\hline
\end{tabular}

pretación. Inspirándonos de la traducción francesa nos permitimos realizar nuestra propia versión: "la parte que, en circunstancias que le permitirían utilizar un remedio fundado en el incumplimiento, tenga derecho a invocar uno de los remedios previstos en el presente capítulo, podrá optar por el remedio de su elección."

Los términos que hemos recogido no tienen carácter exhaustivo, es decir que si el análisis de las traducciones tuviera una finalidad pedagógica podríamos extraer muchísimos más ejemplos, ya que estamos en presencia de unas traducciones de

\section{2nd proofs}


Ejemplo 6 de traducción

\begin{tabular}{|l|l|}
\hline Artículo & Versión en inglés \\
\hline Article 4:119: & $\begin{array}{l}\text { Remedies for non-performance } \\
\text { A party who is entitled to a remedy under this } \\
\text { Chapter in circumstances which afford that } \\
\text { party a remedy for non-performance may } \\
\text { pursue either remedy }\end{array}$ \\
\hline Artículo & Versión en español (A) \\
\hline Artículo 4:119: & $\begin{array}{l}\text { Acciones para casos de incumplimiento } \\
\text { La parte que tenga derecho a ejercitar } \\
\text { alguna de las acciones de este capítulo } \\
\text { en circunstancias que le den también } \\
\text { derecho a aplicar acciones para casos de } \\
\text { incumplimiento, puede utilizar cualesquiera } \\
\text { de dichos medios (negrita añadida). }\end{array}$ \\
\hline Artículo 4.119. & Versión en español (B) \\
\hline & $\begin{array}{l}\text { Remedios por incumplimiento } \\
\text { La parte que tenga derecho a utilizar alguno } \\
\text { de los remedios que le concede el presente } \\
\text { capítulo y que se encuentre al mismo tiempo } \\
\text { en circunstancias que le permitan utilizar } \\
\text { un remedio fundado en el incumplimiento, } \\
\text { puede optar por cualquiera de ellos (negrita } \\
\text { añadida). }\end{array}$ \\
\hline
\end{tabular}

gran calidad. Del análisis de las traducciones hemos aprendido multitud de cosas, como, por ejemplo, que la línea finísima que en la lengua general separa los términos "esencial" y "sustancial" tiene, sin embargo, un gran impacto en el ámbito de los PECL. En efecto, los PECL distinguen el incumplimiento esencial -fundamental non performance- del incumplimiento sustancial -material non performance(Díez Picazo et al. 2002: 162,163). Sin embargo, consideramos que dada la envergadura del análisis jurídico llevado a cabo por los autores de la traducción (B) y puesto que han incluido su propia traducción, hubiera sido de gran utilidad, tanto para juristas como para traductores, que comentaran algunas de sus decisiones a la hora de resolver los problemas de traducción. De forma indirecta, en su comentario del articulo 7.3.2, que regula la "termination of contract" sí que podemos encontrar la razón por la cual prefieren utilizar para su traducción el equivalente funcional "resolución del contrato". Mientras que en los Principios de Unidroit traducen "termination" por "terminación" - para evitar la utilización de términos jurídicos culturalmente marcados - las traducciones al español de los PECL prefieren la utilización del equivalente funcional "resolución” (Díez Picazo et al. 2002 361). En este caso queda justificado ya que los autores reconocen que si bien el có- digo civil sólo regula la "resolución" como un medio judicial de extinción de los contratos, la jurisprudencia ya es unánime y acepta la resolución como medio extrajudicial. Desde este punto de vista, "resolución" es el equivalente funcional de termination.

En el cuadro posterior hemos marcado con un asterisco las soluciones de traducción que consideramos más acertadas. Así pues, podemos ver que, inclusive en el contexto del Derecho internacional, donde la redacción del documento original utiliza una técnica de neutralización para evitar la utilización de términos culturalmente marcados, los traductores utilizan con mayor frecuencia las técnicas de la equivalencia funcional que las de la equivalencia literal. A mayor abundamiento, cuando el traductor opta por la traducción literal - "representación", "daños", "remedios" - incurre en una evidente incoherencia terminológica porque se ve obligado a recurrir al mismo tiempo a sus equivalentes funcionales. Por lo tanto, si hubiéramos fijado como método de traducción la literalidad, ya que el objetivo de este tipo de documentos es tener efectos jurídicos idénticos ${ }^{24}$ en todos los ordenamientos jurídicos donde se puedan aplicar, dicha metodología no se hubiera reflejado en la técnica de traducción adoptada que, como hemos visto, será con mayor frecuencia la de la equivalencia funcional.

\section{Conclusión}

En su trabajo, tanto el comparatista como el traductor siguen un camino de ida y vuelta. En efecto, el comparatista al analizar el Derecho foráneo realiza una transposición lingüística que a la postre puede suponer la transposición del concepto jurídico. ${ }^{25}$ En esta tarea no debe dejarse engañar por las similitudes puramente fonéticas, sino que debe primar el contenido técnico, la figura jurídica. El traductor, por su parte, tiene que hacer suya la lengua de especialidad y dominar la terminología que le es propia, para lo cual utilizará todos los medios que tiene a su alcance el jurista, que no son otros que las fuentes del derecho, además de la doctrina. Así pues, el traductor debe tener un conocimiento profundo del Derecho para poder traducir y debe aplicar la metodología de los comparatistas para la solución de los

24. Muchos autores consideran que la aplicación uniforme del Derecho es una falacia, véase, por ejemplo, Stapleton (2007:26).

25. En ocasiones esta transposición viene por la vía de "recuperar" palabras que ya existían en el lenguaje pero no eran tan utilizadas, como sería el caso de "remedios"; en otras ocasiones será por la vía de dotar de otro contenido nocional a un término jurídico ya existente como "resolución" y en otras situaciones el nuevo término tendrá una connotación clara de su pertenencia al Derecho internacional, como sería "cumplimiento específico" que consideramos un neologismo jurídico.

\section{2nd proofs}


Cuadro recapitulativo

\begin{tabular}{|c|c|c|c|}
\hline Término & Equivalente funcional & Equivalente literal & Otros equivalentes $^{a}$ \\
\hline $\begin{array}{l}\text { Recklessly } \\
\text { Art. 1:301-3 }\end{array}$ & gravemente negligente $^{\star}$ & imprudentemente & temerario \\
\hline $\begin{array}{l}\text { Material } \\
\text { Art. 1:301-5 }\end{array}$ & sustancial $^{*}$ & material & \\
\hline $\begin{array}{l}\text { Purpose } \\
\text { Art. 1:302 }\end{array}$ & objeto & $\operatorname{fin}^{*}$ & finalidad \\
\hline $\begin{array}{l}\text { Conclusión } \\
\text { Art. 2:101 }\end{array}$ & celebración ${ }^{*}$ & conclusión & $\begin{array}{l}\text { formación, } \\
\text { perfeccionamiento }\end{array}$ \\
\hline $\begin{array}{l}\text { Intention } \\
\text { Art. 2:102 }\end{array}$ & voluntad $^{*}$ & intención & \\
\hline $\begin{array}{l}\text { Fraud } \\
\text { Art. 4: } 107\end{array}$ & dolo $^{*}$ & fraude & \\
\hline $\begin{array}{l}\text { Damages } \\
\text { Art. 4:117 }\end{array}$ & $\begin{array}{l}\text { indemnización de daños } \\
\text { y perjuicios* }\end{array}$ & daños & daños y perjuicios \\
\hline $\begin{array}{l}\text { Fraudulent } \\
\text { representation } \\
\text { Art. 4:107 }\end{array}$ & actuación dolosa ${ }^{*}$ & $\begin{array}{l}\text { representación } \\
\text { fraudulenta }\end{array}$ & maquinación dolosa \\
\hline $\begin{array}{l}\text { Remedies } \\
\text { Art. 4:119 }\end{array}$ & acciones $^{*}$ & remedios & $\begin{array}{l}\text { recursos, derechos y } \\
\text { acciones }\end{array}$ \\
\hline $\begin{array}{l}\text { Termination } \\
\text { Art.9:301 }\end{array}$ & resolución* & terminación & extinción, finalización \\
\hline $\begin{array}{l}\text { Fundamental } \\
\text { non-performance } \\
\text { Art. 9:301-1 }\end{array}$ & $\begin{array}{l}\text { incumplimiento } \\
\text { esencial }^{*}\end{array}$ & $\begin{array}{l}\text { no cumplimiento } \\
\text { fundamental }\end{array}$ & $\begin{array}{l}\text { incumplimiento } \\
\text { fundamental }\end{array}$ \\
\hline
\end{tabular}

${ }^{a}$ No siempre recomendados.

problemas de traducción; sin embargo, ello no quiere decir que tenga que utilizar los mismos términos que el comparatista utilizaría en un contexto académico, por ejemplo, ya que la situación comunicativa es distinta. En cuanto a las soluciones terminológicas adoptadas en un contexto internacional, como hemos visto, tampoco serán, de forma automática, la mejor opción para el traductor que recibe un encargo de traducción de un contrato sometido a un Derecho nacional. En este contexto, el abuso de términos neutros y de perífrasis podría hacer dudar al lector español sobre la información que se le está comunicando, el traductor debe mediar entre dos interlocutores que "hablan" lenguajes jurídicos diferentes y, siempre que sea posible, deberá primar la utilización de los equivalentes jurídicos sobre los calcos, préstamos o perífrasis.

\section{Bibliografía}

Alcaraz, E. 2000. El inglés jurídico, (4th ed.). Barcelona: Ariel. 291 pp. Atiyah, P.S. 1990. The Sale of Goods, (8th ed.). Londres: Pitman. 571 pp.

Campana, M. J. 2000. Vers un langage juridique commun en Europe?, European Review of Pri-

$$
\text { vate Law, 33-50. }
$$

Chatillon, S. 2002. «Droit et langue». Revue Internationale de Droit comparé: 687.

Clemente, M. 1988. La facultad de resolver los contratos por incumplimiento. Valencia: Tirant Lo Blanch.703 pp.

Collins, H. 1993. The law of contract (2nd ed.). Londres: Butterworths. 399 pp.

Cornu, G. 2005. Linguistique Juridique, (3rd ed.). Paris: Montchrestien. 443 pp.

David, R. 1985. Les contrats en droit anglais (2nd ed.). París: LGDJ. 382 pp.

David, R., \& Jauffret-Spinosi, C. 1992. Les grands systèmes de droit contemporains (10th ed.). París: Dalloz. 523 pp.

Díez Picazo, L. 1999. Derecho de daños. Madrid: Civitas.367 pp.

Díez Picazo, L., Roca Trias, E., Morales, A.M. 2002. Los Principios del Derecho Europeo de Contratos. Madrid: Civitas. 529 pp.

Forner, J., Garriga, G., Parra, C. 2006. Materiales de Derecho del comercio internacional. Valencia: Tirant lo Blanch. 502 pp.

Hurtado, A. 2001. Traducción y traductología. Introducción a la traductología. Madrid: Cátedra. $695 \mathrm{pp}$.

Lando, O. Beale, H. 2000. Principles of European Contract Law. Parts I and II. The Haghe/London/Boston: Kluwer. $561 \mathrm{pp}$

Lando, O. Beale, H. 2003. Principios de Derecho de los contratos europeo. Perates I y II, edición española a cargo de P. Barres Benlloch., J. M. Embid Irujo y F. Martínez Sanz, Madrid: Colegios Notariales de España, $767 \mathrm{pp}$.

Martín Casals, M. 2002. "Reflexiones sobre la elaboración de unos principios europeos de responsabilidad civil". $2^{\circ}$ Congreso de la Asociación española de abogados especializados en responsabilidad civil y seguro. P. 1-20. Granada. [Disponible en: http://www.asociacionabogadosrcs.org/ponencias/pon2-7.pdf ]

Mayoral, R. 2006. Argumentos en contra de la literalidad en la traducción jurada. Butlletí De l'Associació De Traductors i Intèrprets Jurats.P 1-16.

McGregor, H. 2003. McGregor on Damages. Londres: Sweet \& Maxwell. 1739 pp.

Navas Navarro, Susana. 2000. "El resarcimiento de daños en los Principios europeos de Derecho de los contratos (con especial referencia al Derecho español)". Actualidad civil, 34: $1235-1262$.

Onufrio, M.V. 2007. "Harmonisation of European contract law and legal translation: a role for comparative lawyers.” Vol. 2, pág. 1-14. [Disponible en http://www.indret.com/pdf/429_ en.pdf ]

Perales, M.P. 2001. "El contrato de compraventa internacional de mercancías (Convención de Viena de 1980)" Pace Law School Institute of International Commercial Law. [Disponible en: http://www.cisg.law.pace.edu/cisg/biblio/perales1-74.html ]

Roca, E. 2000. Derecho de daños. Textos y materiales, (3rd ed.). Valencia: Tirant lo Blanch. 326 pp. Schneider, E. 1995. Consequential Damages in the International Sale of Goods: Analysis of Two Decisions. Journal of International Business Law. 615-68.

\section{2nd proofs}


Stapleton, J. 2007. "Benefits of comparative tort reasoning: Lost in Translation." Journal of Tort Law: vol. 1: Iss.3, Article 6. 1-45 pp.

Tallon, D. 1992. "Damages, exemption clauses and penalties". American Journal of Comparative Law. 675-82 pp.

Tallon, D. 1999 «Le choix des mots au regard des contraintes de traduction. In N. Molfessis (Ed.), Les mots de la loi:31, 31-6. París: Económica.

Terral, F. 2002. La Traduction Juridique dans un contexte de pluralisme linguistique. Le cas du Règlement (CE) 40/94 sur la Marque Communautaire: Universitat Autònoma de Barcelona. 489 pp.

Trigo, M.B. 1999. Contratos de servicios. Perspectiva jurídica actual. Granada : Comares. 424 pp. Watson, A. 2000. Legal transplants and european private law. Electronic Journal of Comparative Law, 4.4. [Disponible en: http://www.ejcl.org/44/art44-2.html]

Zweigert, K., \& Kötz, H. 1998. Introduction to Comparative Law, (3rd ed.). Oxford: Clarendon Press. 714 pp.

\section{Diccionarios}

Alcaraz, E., \& Hugues, B. 2001. Diccionario de Términos Jurídicos (6th ed.). Barcelona: Ariel. $706 \mathrm{pp}$.

Cornu, G. 2005. Linguistique juridique (3rd ed.). ParÎs: Montchrestien. 968 pp.

Ribó, L. 1995. Diccionario de Derecho, (2nd ed.). Barcelona: Bosch. 914 pp.

\section{Résumé}

Les textes juridiques produits dans le contexte international répondent à une volonté évidente d'uniformiser le droit, son objectif étant d'obtenir les mêmes effets juridiques dans l'ensemble des pays où ils sont appliqués, et ce indépendamment de la famille juridique à laquelle ils peuvent appartenir. Ce sont des textes dans lesquels les termes neutres ont la priorité et dont la traduction devrait donc tendre à la littéralité. Nous analysons dans cet article des traductions en espagnol de textes internationaux sur les contrats et pour lesquels, contre toute attente, l'équivalence fonctionnelle est la technique la plus utilisée, le choix portant donc sur le terme propre à la culture juridique d'arrivée qui remplit une fonction identique à celle du terme original.

\section{Abstract}

Legal documents drafted in the international context clearly tend towards uniformization of Law as their goal is to obtain the same legal effects in all the countries where they are to be applied, independently of the legal family to which they belong. Since these kinds of original documents prioritize neutral terms we might expect literal translations. However, in this study we have found this is not the case. We have analyzed some translations into Spanish of internation documents regulating international contracts which use neutral terms and we have discovered that the most commonly used translation technique is that of the functional equivalent, i.e. the term belonging to the meta legal culture that has the same function as the source term.

\section{About the author}

Carmen Bestué holds a law degree from the University of Barcelona. After working as an attorney at law for many years she started a new career as a legal translator. She is currently enrolled in her Ph.D. studies at the Autonomous University of Barcelona, where in 2007 she was awarded a Magíster in Translation Studies. From 2003 she has been teaching legal translation at the Facultat de Traducció i Interpretació of the autonomous University of Barcelona. Her research interest include Specialized Translation, Legal Translation, Comparative Law, Language Rights and Minority Languages.

Address: Departement de Traducció, U.A.B., Edifici K-Campus de la UAB, despacho 1014, 08193 Bellaterra (Cerdanyola del Valles), Barcelona.

E-mail: carmen.bestue@uab.cat 